\section{De la casa de doncellas a la cárcel de mujeres: sexualidad y disciplinamiento en Santiago de Guatemala durante el período colonial}

Recibido: Septiembre de 2016 | Aprobado: Enero de 2017

\section{Resumen}

Este artículo, a partir de la experiencia de Santiago de Guatemala, estudia el origen, trayectoria y finalidad de las casas de doncellas y las cárceles de recogidas durante el período colonial. Muestra que las autoridades coloniales, a través de estas instituciones, no sólo alejaron a las mujeres del objeto de su "pecado" o las privaron de su libertad, sino que también las sometieron a un proceso de disciplinamiento. Dispusieron de sus cuerpos y se controlaron sus actividades, obligándoles a asumir los valores que se consideraban normales dentro del orden colonial y a desempeñar ciertas ocupaciones que de manera natural se catalogaban como propias de las mujeres.

\section{Palabras clave}

Historia colonial, Hispanoamérica, cárceles, casa de recogidas, reos Reino de Guatemala, Santiago de Guatemala.
René Johnston Aguilar Licenciado en Historia por la Universidad del Valle de Guatemala y Doctor en Historia Moderna con Diploma de Estudios Avanzados de la Universidad de Navarra, España. Actualmente trabaja como profesor en la Universidad el Istmo de Guatemala y Universidad del Valle de Guatemala. Entre sus publicaciones se encuentra, "Comercio en el Mar del Sur ciertos aspectos prácticos del intercambio comercial marítimo, Siglo XVIII", en: Revista de Historia 43 (enero-junio 2001),143-166. johnstonrene@gmail.com
From the Maidens' House to the Women's Prison: Sexuality and Discipline in Santiago de Guatemala during the Colonial Period

\begin{abstract}
Based on the experience of Santiago de Guatemala, this article studies the origin, trajectory and purpose of the maidens' house and women's prison during the colonial period. It shows that the colonial authorities, through these institutions, not only alienated women from the object of their "sin" or deprived them of their freedom, but they also sought to discipline them in moral terms. Colonial authorities disposed of their bodies and controlled their daily activities, forcing them to assume the values that were considered normal in the colonial order and to perform occupations that were naturally classified as belonging to women.
\end{abstract}

\section{Keywords}

Colonial history, Hispanic America, prisons, casa de recogidas, prisoners, Kingdom of Guatemala, Santiago de Guatemala. 


\section{Introducción}

Las mujeres, al igual que el resto de actores sociales que hicieron parte del jerárquico orden colonial, tenían un rol bien definido en la sociedad. Las autoridades, a través de un conjunto de normas civiles y doctrinas cristianas, le asignaron el estatus de subordinadas y sumisas.' Según Bianca Premo, esta visión sobre el lugar que debían ocupar las mujeres en ese orden social estaba articulada a la noción de patria potestad, o los derechos que un padre tenía sobre su familia. Esta noción provenía de la ley romana, pero fue elaborada para el contexto español en los códigos de Las Siete Partidas, en el siglo XII. En su forma española codificada en las partidas, el poder (en latín potestas) era el de un hombre sobre sus subordinados. Este poder se encontraba en varios niveles de la sociedad, de la casa al trono. El poder de un padre sobre su familia (incluso de su esposa), de un amo sobre su esclavo, del obispo sobre los curas y, finalmente, del rey sobre sus súbditos. Estas eran las jerarquías interrelacionadas en las cuales estuvo basado el orden cívico. ${ }^{2}$

La primacía del hombre sobre la mujer se iniciaba desde su nacimiento y era él quien heredaba los títulos. El derecho castellano

\footnotetext{
1 Una buena descripción de cómo era la regulación jurídica de la familia, incluyendo el estatus de la mujer ante la ley, se encuentra en José María Ots Capdequí, El estado español en Indias, México, Fondo de Cultura Económica, 1993, pp. 95-100.

2 Bianca Premo, "Pena y protección: Delincuencia juvenil y minoridad legal en Lima Virreinal, siglo XVIII", en Revista Histórica, vol. XXIV, n 1, Pontificia Universidad Católica del Perú, 2000, pp. 85-120. Sobre las leyes de minoridad y mujeres también puede verse Las Siete Partidas, glosadas por el señor Alfonso Montalvo, Venecia: Luacantonio de Giunta Florentino, 1501, Parte. VI, Tít. XVII, Ley III.
}

las trató siempre como menores de edad que necesitaban protección. Dentro de la vida familiar, siendo niña o soltera, quedaba bajo la autoridad y protección tutelar del padre. Si el padre moría, quedaba bajo la tutela de la madre o parientes o de la persona que fuera designada por un juez. ${ }^{3}$ Las doncellas menores de 25 años y las casadas de cualquier edad requerían de licencia de su tutor o marido para realizar cualquier tipo de transacción con sus bienes. La mujer no podía, ni en su mayoría de edad, desempeñar puesto público alguno, ni ejercer funciones judiciales. Se le consideraba tan poco responsable que no podía ser testigo en testamento, ni ser fiadora y tampoco podía ser encarcelada por deudas. ${ }^{4}$

Prudencia, justicia, fortaleza y templanza, las virtudes cardinales en el catecismo de la doctrina cristiana, eran precisamente las más recomendadas para las mujeres de cualquier condición. Honestidadylaboriosidadcompletaba la imagen ideal, que podía estar adornada con la sumisión y docilidad. Se consideraba que la mujer debía de ser honrada y cuidadosa de su buen nombre y el de su familia, respetuosa y fiel con su esposo, generosa, ayudadora de los necesitados, amorosa con todos, trabajadora, madrugadora, buena gobernadora de su casa y pacífica, y debía hilar, tejer, permanecer en casa y no estar ociosa, sino haciendo labor. ${ }^{5}$

Sin embargo, al margen de lo establecido en los códigos y de las recomendaciones piadosas, la

3 Ots Capdequí, El estado español, pp. 73-100.

4 Recopilación de Leyes de Indias, Libros II (Título V, Ley IV); Libro V (Títulos V), Libro XII Título V, Ley IV).

5 Josefina Muriel, Los recogimientos de mujeres, respuesta a una problemática social Novohispana, México, UNAM, 1974, pp. 13-28. 
sociedad imponía sus propias normas y criterios: veía con recelo a las mujeres solteras y se burlaba de los maridos que permitían ser gobernados por sus esposas. Se necesitaba la aportación de la fuerza laboral femenina, pero no capacitaba a las mujeres para realizar trabajos productivos $y$ razonablemente remunerados. ${ }^{6}$ Cerraba los ojos ante la presencia de gran cantidad de solteras y viudas, y suponía que todas las niñas llegarían a ser esposas y madres de familia. Procuraba que las fortunas familiares pasaran por manos femeninas a través de dotes y herencias, pero esperaba que fueran los hombres quienes las administrasen. En estas circunstancias, la realidad rebasó los prejuicios, y las formas de convivencia familiar que se generalizaron en la colonia tuvieron sus propias características y fueron definidas por la actuación de las mujeres.?

Las mismas acciones y prácticas sociales de las mujeres contribuyeron a cuestionar el estatus de subordinadas que les asignaron en el orden social colonial. Por ejemplo, la licencia marital podía extenderse cada vez que la esposa la requería, o con carácter permanente, para todas las operaciones económicas que pudieran presentarse a futuro; también podía proporcionarla el juez, por ausencia del marido o por negativa injustificada de éste a otorgarla

6 En algunas casas de recogidas las mujeres si recibían remuneración por su trabajo. En una una casa en Lima, por ejemplo, algunas "doncellas pobres" atendían enfermas de un hospital y se les pagaba por ello, lo cual era abonado "a su dote, para poder casarse". Lidia Martínez Alcalde, "El Colegio-Recogimiento de la Caridad de Lima (1562-1620)", en Revista Hispania Sacra Vol. 53, $n^{0} 108$, España, Consejo Superior de Investigaciones Científicas, 2001, pp. 435-454.

7 Juan José Marín, "Perspectivas y problemas para una historia social de la prostitución", en Revista de la Universidad de Costa Rica nº 13, Costa Rica, Universidad de Costa Rica, 2001, pp. 53-65. e, incluso, cabía realizar cualquier transacción, en firme y con todas sus consecuencias, en espera de que el marido ratificara el acto a posteriori. Las escrituras notariales dan testimonio de la frecuencia con que las esposas realizaban operaciones financieras, con o sin licencia de sus cónyuges. Asimismo, la ley no era un impedimento insalvable para que las casadas gozaran de cierta autonomía. Prueba de ello es que entre 1770 y 1773 , el $49 \%$ de todas las propiedades inmuebles en Santiago de Guatemala pertenecían a mujeres. ${ }^{8}$

El matrimonio, institución central en la reproducción y mantenimiento del orden social colonial, también fue transgredido por varias mujeres. Como lo han demostrado varios estudios, entre esos el de Yolanda Mejía Camilo sobre Lima (Perú), aunque la educación de la mujer estaba encaminada a la obediencia en el matrimonio, el mayor porcentaje de participación de divorcio era por parte de las mujeres, pues muchas de éstas se veían sometidas a una violencia sistemática en la vida familiar y social. La mujer también exigía fidelidad del marido; consideraban que el adulterio masculino era un hecho grave, deshonraba y denigraba a la mujer, y era causa justa de divorcio. ${ }^{9}$

La castidad fuera del matrimonio o la fidelidad dentro de éste que se pregonaba también estuvo alejada de realidad familiar colonial.

8 René Johnston Aguilar, De Santiago de Guatemala a la villa de Antigua Guatemala, transformación y vida social ante una crisis, Tesis para optar al título de Licenciado en Historia, Guatemala, Universidad del Valle de Guatemala, 1997.

9 Yolanda Mejía Camilo, "Divorcios en Lima del Siglo XVIII (17001750)", en Alma Mater nº 13-14, Lima, 1997, 57-62. 
Relaciones sexuales consideradas ilícitas, entre ellas el amancebamiento, el concubinato o la prostitución, estuvieron a la orden del día. Las autoridades laicas y eclesiásticas, ante la imposibilidad de controlar la sexualidad dentro de los cauces del matrimonio, respaldaron la fundación de "casas de mancebías" que funcionaban como prostíbulos o burdeles, tanto en España como en las colonias americanas. $Y$ también acudieron al establecimiento de casas de doncellas, casas de recogimiento y cárceles para mujeres. ${ }^{10}$

Este artículo, a partir de la experiencia de Santiago de Guatemala, estudia el origen, trayectoria y finalidad de estas tres últimas instituciones. Muestra que en este territorio las autoridades coloniales, a través de las casas de doncellas o las cárceles de recogidas, las mujeres no sólo eran alejadas del objeto de su pecado o privadas de su libertad, sino que también terminaron siendo sometidas a un proceso de disciplinamiento. Se dispuso de sus personas y se controlaron sus actividades, obligándoles a asumir los valores que se consideraban normales dentro del orden colonial y a desempeñar ciertas ocupaciones que de manera natural se catalogaban como propias de las mujeres.

\section{Las casas de recogidas 0 arrepentidas en el orden colonial}

Las casas de recogimiento existieron en las principales ciudades de Hispanoamérica desde el siglo XVI. Al igual que otras instituciones que

10 Ana María Atondo Rodríguez, El amor venal y la condición femenina en el México colonial, México, Instituto Nacional de Antropología e Historia, 1992, pp. 1-12. se desarrollaron en los territorios de ultramar, estas casas ya se habían contemplado y puesto en práctica en la misma España. En efecto, durante ese siglo comenzó a existir en España una preocupación por intentar resolver los problemas del alto índice de delincuencia, la mendicidad y la prostitución femenina. Una alternativa era la del encierro en las cárceles de mujeres llamadas Galeras, nombre que fue tomado del castigo de remar en las galeras a la que fueron destinados tantos hombres que sirvieron en las armadas en ese tipo de barcos. Estos encierros eran centros de reclusión para mujeres públicas o casas de recogidas para mujeres arrepentidas, cuya finalidad era la de servir como correccional o reformatorio; de ahíque muchas de ellas tomarán la denominación de Casas de Arrepentidas."

Según Fernández Cúcala, el discurso generado de la idea de las casas-galera para mujeres lo formularon fundamentalmente el Doctor Cristóbal Pérez de Herrera (1598), y la madre Magdalena de San Jerónimo. Lo más interesante de la propuesta del primero estriba en que, aunque consideraba necesario el castigo para conseguirmodificarsus conductas, a lavez plantea que las mujeres trabajasen en varias tareas, lo que se traduciría en una autofinanciación del encierro. Además, para llenar el vacío dejado por la falta de penas intermedias para mujeres, ideó los encierros femeninos. Sin embargo, fue una monja, la madre Magdalena de San Jerónimo, quien propuso al Rey la puesta en práctica del plan de Pérez de Herrera, con unas pequeñas reformas que se referían, básicamente, al trato

11 María Dolores Pérez Baltazar, Origen de los recogimientos de mujeres, Madrid, Universidad Complutense, 2007, pp. 1-11. www. monografias.com. Consultado el 10 de febrero de 2012. 
que recibían las reclusas, pues ésta se muestra mucho más enérgica y dura en la aplicación de castigos corporales, etc. ${ }^{12}$

En los territorios hispanoamericanos, el primer centro de recogimiento que existió fue uno para prostitutas que, bajo el reinado de Carlos I, se fundó en Santo Domingo en 1526. A través de una cédula real, se le concedió permiso a un hombre acaudalado "para que sirviendo de ejemplo a ese pueblo, se cortase los excesos y escándalos". En época de Felipe II se planteó la necesidad de hacer recogimientos para "las mujeres mozas perdidas, que andan por las calles ofendiendo a nuestro señor" y se advertían de peligros que se cernía sobre la población femenina. ${ }^{13}$ La corona española, entre 1572 y 1575 , expidió nuevas normatividades tendientes a reglamentar el funcionamiento de los burdeles públicos novohispanos. Establecieron, entre otras cosas, que las mujeres reclutadas para trabajar en ellos debían ser huérfanas o abandonadas por sus padres. Con esta medida la Corona manifestaba coherencia respecto a los entonces valores dominantes, pues se consideraba de que la mujer desarraigada de la estructura familiar era proclive a la prostitución. ${ }^{14}$

Pero la sociedad de la época mostraba una actitud ambigua respecto a las mujeres familiar y económicamente desarraigadas; a la vez que eran consideradas en cierta medida

12 Mariana Fernández Cúcala, "La casa de recogidas Nuestra Señora de la Caridad o del Refugio 1848-1870", en Historia Contemporánea n 21 , Barcelona, Universidad de Barcelona, 2000, pp. $485-521$.

13 J. Muriel, Origen de los recogimientos, p. 24-26.

14 A. Atondo, El amor venal, pp. 1-13. como las naturales candidatas para satisfacer los apetitos sexuales masculinos marginales al matrimonio, se manifestaba hacia ellas un afán proteccionista. Asegurar que lograran unirse matrimonialmente se convirtió en un propósito de algunas instituciones de beneficencia o de individuos deseosos de actuar conforme a los principios cristianos de la caridad. Dado que la tradición imponía, al menos a la mujer española, la necesidad de poseer una dote como requisito matrimonial, proporcionaron con este fin fondos destinados a las doncellas huérfanas o pobres para que pudieran casarse. Por ejemplo, los miembros de la tercera orden franciscana o determinadas cofradías hicieron donaciones con tal objeto. ${ }^{15}$

En 1526, precisamente, se creó un establecimiento de este tipo en el Virreinato de Nueva España. La primera fue para el recogimiento de "mujeres perdidas" fundada por personas de buena voluntad de la ciudad de México. No obstante, debido a la extensión territorial y a la notable población en muchas ciudades, también las hubo en Puebla, Tlaxcala, Veracruz, Oaxaca, etc., siendo fundados bajos los auspicios financieros de la corona, las autoridades locales y grupos de personas particulares "de buena voluntad". Si bien éstas se inspiraron en las españolas, en cada región se adaptaron a sus necesidades; por ejemplo, en la ciudad de México había una para el recogimiento de "mujeres con incontinencia, perdidas, inquietadoras, enamoradas y prostitutas"; otra para ayudar a mujeres novohispanas con pocas posibilidades económicas; para mujeres

15 A. Atondo, El amor venal, pp. 12-13. 
casadas en "depósito" (en proceso de divorcio), viudas, pobres, "virtuosas de calidad", etc., y para doncellas españolas honestas. ${ }^{16}$

En México, primero se fundaron los recogimientos de niñas y jóvenes que funcionaban como colegios. Después surgieron los recogimientos de mujeres arrepentidas, es decir, las mujeres que por su propia voluntad deseaban dejar la vida pública que llevaban para entregarse a la oración y penitencia. Más tarde se fundaron recogimientos para mujeres casadas, viudas, divorciadas y solteras. Las mujeres que se acogían generalmente lo hacían por el resto desus vidas debido a su pobrezay a los pocos medios que tenían para valerse por sí mismas. Finalmente, se hicieron las dedicadas a las delincuentes. Estas instituciones se puede clasificar en dos clases: las voluntarias, cuyo fin era la protección y ayuda a la mujer, y las que servían como correccionales para las mujeres sentenciadas por los tribunales. En 1572 se fundó el Recogimiento de Jesús de la Penitencia que funcionó para acoger a mujeres "enamoradas, arrepentidas y perdidas", y entraban en ella "mujeres españolas distinguidas, jóvenes españolas, pecadoras de calidad o jóvenes pecadoras convertidas". Esta institución funcionó hasta finales del siglo XVII, cuando se convirtió en convento concepcionista en un bello edificio de grandes proporciones que aún sobrevive. Al disolverse la anterior casa de recogimiento, se fundó (y funcionó hasta finales del siglo XVII) otra denominada Hospital de Misericordia o Recogimiento de la Misericordia, que funcionó para recoger a "mujeres perdidas, alegadoras, mancebas y señoras divorciadas" que

16 J. Muriel, Los recogimientos de mujeres, p. 30. buscaban redención, como hospital para mujeres con enfermedades contagiosas y como centro correccional en la que no se les enclaustraba de por vida, sino sólo se les encerraba durante el tiempo necesario para su corrección y después se les dejaba libres. Otras fueron: El Recogimiento de Señoras Casadas de Santa Mónica; el recogimiento para mujeres pobres y virtuosas de calidad Nuestra Señora de la Asunción; Santa María Magdalena, recogimiento para prostitutas, $y$ otras instituciones con funciones similares, tanto en la capital del virreinato como en otras ciudades. ${ }^{17}$

En Santiago de Guatemala, ciudad perteneciente al Virreinato de Nueva España, uno de los primeros pasos para crear instituciones de este tipo se dio en 1571. Este año se dispuso fundar una Casa de Doncellas Huérfanas y Pobres (también conocida como "El Niñado"). Esta iniciativa fue secundada por Diego de Carbajal y Jerónimo Romero. Carbajal, miembro del círculo religioso del primer Obispo de Guatemala, Francisco Marroquín, fue sacerdote de la diócesis de Cuatemala, arcediano desde 1580 y uno de los prebendados de la Catedral de Guatemala desde la época del ya citado primer Obispo. Se hizo notable, además, por su actuación en el Concilio Provincial celebrado en la ciudad de México (1555), y a ello se debió indudablemente su designación como primer Comisario del Santo

17 Muchas de estas instituciones llevan el nombre de Magdalena - María Magdalena porque antiguamente se pensaba que su arrepentimiento y conversión se debía a que había sido una prostituta que se había arrepentido gracias a Cristo y que además había pasado sus últimos días como penitente en las cuevas de Marsella en Francia, arrepentida de su pasado y consagrada a Dios como penitente y ermitaña. Los ermitaños usaban ropa andrajosa 0 muy poca, a María Magdalena se le representaba vestida sólo con una cabellera abundante. 
Oficio en Santiago de Guatemala. Al morir dejó varias fundaciones, entre otras, una de 7,000 pesos para casar doncellas pobres del beaterio de Santa Rosa, las cuales debían recibir 250 pesos de dote cada una. Romero, Chantre de la Iglesia Catedral, también contribuyó para sacar adelante la fundación de una casa para doncellas. El 30 de mayo de 1591, otorgó testamento ante los oficios del escribano Cristóbal de Aceituno y dejó la suma de 35,000 tostones destinados a la fundación de una casa de recogimiento de doncellas pobres, hijas de conquistadores o descendientes de aquéllos. El 5 de julio de ese año se extendió escritura del colegio, en el cual habría completa clausura con la condición de que al llegar a la pubertad las pupilas quedaban en libertad de tomar estado de religiosas en los conventos de la ciudad o dedicarse a otro género de vida. Fue aprobado por el rey Felipe II, pero añadió en las cláusulas de su cédula, que en ningún tiempo ni por causa alguna pudieran ser depositadas en dicho colegio mujeres de mal vivir o esposas acusadas de infidelidad matrimonial. ${ }^{18}$

Las primeras gestiones para la fundación de una casa de recogidas las hizo el obispo fray Andrés de las Navas y Quevedo (1622-+1701) por medio de una carta dirigida al rey de España con fecha de julio de 1683 , según consta en una cédula del 14 de noviembre de 1686. Agustín Estrada Monroy opinó que entre el Presidente de la Audiencia y el obispo Navas y Quevedo había existido un cisma. De manera que fue sólo hasta el 5 de septiembre de 1715 que la Real Audiencia

18 Rodolfo Hernández Méndez, "La Casa de Doncellas", en AEHC, Asociación de Estudios Históricos en Centroamérica, 2005, http:// www. afehc-historia-centroamericana.org/index.php?action=fi_ aff\&id=679. Consultado el 18 de julio de 2012. otorgó licencia para llevar a cabo la fundación de la Casa de Recogidas, en vista de haber un fondo de dos mil pesos, más el crédito de mil, por donación del Obispo fray Juan Bautista Álvarez de Toledo. ${ }^{19}$

La decisión de crear la Casa de Recogidas se sustentó en las visiones que se desarrollaron en el siglo XVIII sobre la necesidad de la vigilancia médica de las mujeres públicas. Se trató de controlar el sector social marginal, en el que todo se confundía y entremezclaba; no había mucha diferencia entre decir vagabunda y ladrona, vagabunda y prostituta, prostituta y ladrona, pues una actividad podía conducir a la otra y una situación conducirlas hacia las demás. Se pasó así, y con mayor fuerza, a la necesidad de la vigilancia médica de las mujeres públicas. El control de la prostitución fue reclamado desde todas las instancias como medio de evitar el contagio de las enfermedades venéreas. Adicionalmente, y en respuesta a lo anterior, se fueron fomentando en España y en ciudades hispanoamericanas, los correccionales o recogimientos, como más tarde se los denominaría. Se fundaron casas de recogidas en Barcelona (1700), Alicante (1743), Orihuela (1745) y Málaga (1792). ${ }^{20}$ En ciudades hispanoamericanas, como La Habana, Cuba, también tuvo lugar durante este período la fundación de una Casa de Recogidas,

19 Archivo General de Centro América (AGCA), A1.2.1 leg. 2824 exp 75067; J. Pardo, Guía de la Antigua, pp. 68-70; Agustín Estrada Monroy, Datos para la Historia de la Iglesia en Guatemala, Tomo I, Biblioteca "Goathemala" volumen XXVI, Guatemala: Sociedad de Geografía e Historia de Guatemala, 1972, pp. 345-374; Fray Francisco Ximénez, Historia de La Provincia de San Vicente de Chiapa y Guatemala de la Orden de Predicadores. Tomo IV, Libro VI., Chiapas, Concultura, 1999, pp. 21 y 304.

20 M. Fernández Cúcala. "La casa de recogidas Nuestra Señora de la Caridad". 
destinada a prevenir y corregir la prostitución en la mujer. Según Rolando Álvarez Estévez, por entonces, las mujeres de la clase aristocrática vivían plácidamente dentro de "los prejuicios impuestos por la sociedad". En gran medida, su papel era eminentemente decorativo, así como de reproductoras. En lo que respecta a la clase media, no se perdonaba a quien violara las normas sociales. En los estratos más bajos la cosa era distinta porque las mujeres corrían el peligro de que si no se comportaban de acuerdo con la moral prevaleciente, podían ser remitidas a la Casa de Recogidas. ${ }^{21}$

El inadecuado funcionamiento de la Casa de Doncellas en Santiago de Guatemala fue otro factor que incidió en la creación de la Casa de Recogidas. Desde mediados del siglo XVII, varios funcionarios expresaron que el propósito con el cual se había creado la primera institución no se estaba cumpliendo. Don Domingo Ruiz Lozano, a través de una carta dirigida al rey Felipe IV, protestó porque al Colegio de Doncellas se estaban enviando mujeres de vida dudosa, que no sólo eran las linajudas, sino "mujeres depravadas" que llegaban a confundirse con las muchachas que se trataba de educar. El rey envió una cédula en la que estipuló se cumpliera la orden de no admitir mujeres de este tipo. Esa cédula real no tuvo el efecto esperado pues Ruiz Lozano volvió a protestar ante el rey que se estaban enviando "mujeres depravadas, criminales de todas las razas y condiciones". Ante esa situación, en 1765 el rey ordenó la clausura definitiva del Colegio de Doncellas, cuando a aquel edificio ya se le conocía

21 Rolando Álvarez Estévez, La Casa de Recogidas. Una Experiencia Colonial en Cuba, Habana, Cubarte. 2007, p 1. como "Casa de Recogidas". Esa primera casa se ocupaba de transformar la vida de las pecadoras arrepentidas de la vida que llevaban, por eso en México (y posiblemente también en Guatemala) se les conoció como "las arrepentidas".22

\section{Del objeto y trayectoria de la Casa de Recogidas}

La Casa de Recogidas de Santiago de Guatemala tuvo funciones similares a las casas establecidas en otros territorios del Virreinato de Nueva España e Hispanoamérica. Según lo establecido por Josefina Muriel, en estas instituciones "se amparaba a la ramera, a la prostituta, dándole un techo bajo el cual tendrá la oportunidad de una vida en paz con su conciencia, a las mujeres casadas que tendrían problemas con sus maridos se les ayudaba a solucionarlos, procurando la reconciliación matrimonial". 23 Se depositaban y amparaban a mujeres con problemas económicos, viudas, mujeres de mala o ligera conducta, pobres o limosneras. También se acogía a las mujeres que concebían hijos ilegítimos y a las que estaban en proceso de anulación de su matrimonio. Otras mujeres eran depositadas allí por su padre o madre, esposo, hermano, maestro, por no ir a misa, ser hijas rebeldes, no obedecer o ser malas hijas, así como por denuncias o recomendaciones de sus esposos, maestros, padres. Otras veces, se les internaba por "no querer a su madre" o "no servir bien a sus amos" o huir de sus casas, entre otras razones.

22 J. Muriel, Los recogimientos, p. 30.

23 Este y otros conceptos de la vida de la mujer colonial y la fundación y organización de los recogimientos en el Virreinato de la Nueva España son de J. Muriel Los recogimientos, p. 23. 
En estas casas encontraban albergue gratuito las mujeres pobres y las jóvenes sin recursos que fueran arrastradas a la prostitución o tuvieran que ser depositadas en dicha institución por disposición judicial o depositadas por su marido o un pariente. El Reglamento de la Casa de Recogidas de La Habana, por ejemplo, decía que el principal objetivo consistía en:

\section{[...] separar a la mujer incorregible de la Ciudad, de los presos de la cárcel política y se precisaba que allí se albergarían doncellas pobres y expuestas a la relajación; para depositarlas con destino a matrimonio y para divorciadas y para delincuentes escandalosas e incorregibles; no debiéndose permitir la admisión ni la salida de ninguna sin previa orden escrita de los tribunales."24}

La particularidad de la casa de Recogidas de Guatemala radicó en el hecho de que en un mismo edificio se llevaban a cabo toda la multiplicidad de funciones previamente mencionadas. Es decir, no sólo funcionó como casa de arrepentidas sino que también fue colegio y cárcel de mujeres, preventiva y correccional. Desde su fundación, por tanto, se recibieron a mujeres de cualquier calidad y estrato socioeconómico. Esta singularidad del caso guatemalteco se puede explicar, en parte, por la escasez de recursos para la construcción y manutención de las casas de recogimiento. Los escasos fondos de mantenimiento provenían de ayudas que los administradores recibían de algunos benefactores. Varios informes dan cuenta de las difíciles condiciones económicas que enfrentó La Casa de Recogidas. Por ejemplo,

24 R. Álvarez Estévez, La Casa de Recogidas. en 1765 la madre rectora informó que muchas mujeres estaban en peligro de muerte por la disentería y que había necesidad de comprar medicinas, pero no tenía dinero. Como la dotación asignada por el Ayuntamiento nunca alcanzaba para cubrir los gastos, se procuraban ingresos por otros medios. Elaboraban hilo de algodón, que doce de ellas salían a vender a la calle, con lo cual lograban un promedio de tres reales en los días que salían. También sufragaban sus gastos con limosnas y, en casos extremos, con contribuciones provenientes de la bolsa de la misma rectora. ${ }^{25}$

Estas difíciles condiciones económicas se agudizaron tras la destrucción que sufrió la sede de la casa de recogidas a causa de un terremoto que ocurrió en Santiago de Guatemala en 1773. Después del terremoto, un maestro de obras, Bernardo Ramírez, hizo una "inspección de ojos" del estado en que quedó el edificio e hizo recomendaciones de lo que se debía hacer. Dijo que el edificio quedó totalmente en ruinas $y$ que el único espacio que no se cayó fue un salón en el que dormían y vivían toda la población de ese centro, que consistía de 45 mujeres "más las otras que venían de Escuintla". El maestro de obras repitió una vez más lo que se decía constantemente, que "las mujeres debieron de vivir en muy precarias condiciones ya que no tenían dinero para comprar sus alimentos y pasaban frío a causa de la lluvia y el estar expuestos a las inclemencias del tiempo". A fin de cocinar sus alimentos construyeron un fogón en el techo y sacaban el agua de una pila que no se destruyó. Pidió que se reconstruyeran los muros para evitar la fuga de las reas, que se reconstruyera
25 AGCA, A1, leg. 5918, exp. 51065. 
el oratorio y se reacomodara a las otras mujeres. De las recomendaciones dio el maestro de obras sólo se autorizó la reconstrucción del oratorio. ${ }^{26}$

En otro informe, que data del 4 de septiembre de 1775, la rectora les explicó a las autoridades las difíciles circunstancias por las que estaban pasando por la baja en la asignación de "solo medio real diario para la alimentación", que les permitía una única comida, el almuerzo. Explicaba la rectora que antes de la ruina de la ciudad por el terremoto de 1773, la casa recibía una contribución diaria de 20 reales para la compra de sal, leña y tortillas y dos reales al día para la compra de carne. También, por medio de la obra pía fundada por el obispo Álvarez de Toledo, a principios de siglo, se recibían cuatro pesos diarios para utilizarlos en la alimentación. Por ello solicitó que le volvieran a asignar la misma cantidad de antes del terremoto. De igual tenor fueron los comentarios que la madre rectora hizo ante la Audiencia (localizada en el Palacio Real) en 1775. En esta oportunidad, aparte de pedir que repararan el edificio que estaba "en deplorables condiciones", solicitó que les ayudaran con dinero para mantener a las mujeres porque como "estamos tan pobres, tienen que salir a pedir limosna."27

El terremoto de 1773 tuvo implicaciones de mayor impacto en la trayectoria de la Casa de Recogidas. Bernardo Ramírez, el maestro de obras que inspeccionó el edificio, recomendó el traslado de los reos de las cárceles de la ciudad y de las mujeres de la Casa de Recogidas al antiguo edificio de la Universidad de San Carlos, mientras

26 AGCA, A1.54 leg 5351, exp. 45162.

27 AGCA, A.1 leg 5918, exp. 51065. que se reparaba el edificio. Pero como era difícil que las autoridades tomaran una decisión, pasó más de un año antes de que se recibiera la autorización. Mientras tanto se logró que las 45 mujeres que vivían allí fueran trasladadas al antiguo Colegio Tridentino, contiguo al edificio de la Universidad. Posteriormente, las mujeres y los reos de las otras cárceles de la ciudad fueron trasladados a la Universidad, que compartía el edificio con la fábrica de pólvora. Debido a las estrecheces económicas que sufrió toda la población y el estado, la institución ya no recibió suficientes fondos para poderse mantener. Con el traslado al Valle de la Ermita también se trasladó la Casa de Recogidas a la Nueva Guatemala de la Asunción. Con ello terminaron las funciones que había proporcionado a las mujeres por casi un siglo. En ese nuevo sitio dejó de ser una verdadera casa de recogimiento como fue concebida originalmente, porque ya no albergó a la amplia variedad de estratos sociales y mujeres con diferentes problemas, como lo había estado haciendo hasta ese momento, y sólo se trasladaron a las reclusas de la cárcel. Aunque sólo hubiera reclusas en la Nueva Guatemala continuó llamándose la Casa de Recogidas, para eventualmente, cambiar su nombre al de Cárcel de Mujeres. ${ }^{28}$

\section{La vida en la cárcel}

La cárcel de mujeres, al igual que la casa de doncellas, fue administrada porórdenes religiosas, y sólo hacia las primeras décadas del siglo XIX la administración cambió a un sistema burocrático.

28 Hay muchas referencias al respecto en el AGCA, por ejemplo A.19.3 leg.4540, A2.2 leg. 139 exp. 2543; y en el Archivo General de Indias, signatura Guatemala 657. 
En los documentos revisados se pudo establecer que había una madre rectora o gobernadora, un mayordomo de Provisión, y una portera que cuidaba el acceso del exterior. ${ }^{29}$ La gobernadora tenía que controlar que cada rea tuviera suficiente rancho (alimento diario); cerciorarse de que se les organizaran en "compañías" para que trabajaran hilando y vendiendo los productos a fin de lograr algunosfondosala institución. ${ }^{30}$ Todos lossábados, al menos en teoría, los jueces debían visitar las prisiones, incluyendo la Casa de Recogidas. El juez era acompañado por su escribano o secretario y anotaba todo lo concerniente a cada uno de los reos.

Los informes de estas autoridades coloniales permiten reconstruir el número de reas, las razones de su detención, el tipo de delito y contra quién, la hora de la detención, su estado civil, su oficio y, a veces, la casta. Por ejemplo, en las visitas registradas en 1765 se dice que en la Casa había 18 mujeres presas el 18 marzo; el 30 de ese mismo mes, había 26; a principios de abril, eran 30; el 6 de ese mes, eran 28; los últimos registros de ese año-el 13 y 27 -señalan que había 16. Otro informe fechado en 1800 , al solicitar los gastos de mantenimiento de la institución, dice que el número de reas variaba de 48 a 56 . En otro documento que especifica el delito, la condena y el número de presas, en la cárcel de la Nueva Guatemala de la Asunción, ${ }^{31}$ se menciona que el 22 de diciembre en 1799 había 102 reclusas.

\footnotetext{
29 AGCA, B.109.1 leg 2341 exp. 46976.

30 Pardo, Guía de la Antigua, p. 142.

31 Esta información es producto de la información sobre las penas a los reos y reas con el mismo tipo de delito en los "Libros de Visitas" anotados en las citas anteriores para los mismos años de 1765,1799 y 1800.
}

Estaban presas por ebrias, 12; por agresión (haber causado heridas), dos; amancebadas, 63; ladronas, 17; juegos en su casa, dos; a petición de sus padres, dos, y 24 indias holgazanas. En cambio, el 30 de diciembre de 1800 había 57: 5 ebrias, 46 amancebadas, una ladrona, 2 por juegos en su casa y otras 3 por venta de chicha y aguardiente ilícito. ${ }^{32}$

De acuerdo a los Libros de Visitas de Guatemala, las mujeres estaban detenidas por delitos sexuales como amancebamiento, concubinato, ilícita amistad o por "mal entendidas" o rameras (mujeres públicas); robos y homicidios; por ebrias, holgazanas y jugadoras, o por producir o vender aguardientes ilegales. Otras eran depositadas por denuncias o recomendaciones de sus esposos, maestros, padres o tutores; por "no querer a su madre", o "no servir bien a sus amos y sirvientas por dejar el trabajo sin permiso", o por huir de su casa. ${ }^{33}$

En el libro de visitas de 1765, junto a mujeres recluidas por delitos sexuales, aparecen reclusas condenadas por robo y hurto, criminales homicidas y agresoras, chicheras (productoras de aguardientes ilícitos), juego, etc. Se detallan los delitos de la siguiente manera: homicidio, dos; agresión, tres; robo, cuatro; chicheras, dos; ebrias, cuatro; dos por no querer declarar en un juicio; una por fuga; dos por delitos sexuales: prostitución; por mal entendidas, dos; amancebadas, catorce; relaciones ilícitas y mal entendidas, cinco; alcahuetas y consentidoras, tres. En depósito se encontraban: por no ir a misa,

32 AGCA, A1.28, leg 4011, exp 16402.

33 AGCA, en "Libro de Visitas" año 1765, leg 2260, exp 16402; año 1799 y 1800; A.1.2.8, leg 4011, exp. 30605. 
Cuadro 1. Población de Reclusas por tipo de delito

\begin{tabular}{|l|c|c|c|}
\hline \multicolumn{1}{|c|}{ Delito } & $\mathbf{1 7 6 5}$ & $\mathbf{1 7 9 9}$ & $\mathbf{1 8 0 0}$ \\
\hline Homicidio & 2 & & \\
\hline Agresión & 5 & 2 & 1 \\
\hline Robo & 4 & 17 & 3 \\
\hline Hurto & & & 5 \\
\hline Fabricar licor clandestino & 2 & 12 & \\
\hline Ebria & 4 & & \\
\hline Fuga & 1 & & \\
\hline No querer declarar en juicio & 2 & 2 & \\
\hline Indias holgazanas (sic) & 2 & 2 & \\
\hline Juego & 1 & 63 & \\
\hline Sexual & 26 & 24 & \\
\hline En depósito & & 102 & \\
\hline Total & 49 & & \\
\hline
\end{tabular}

dos; a pedido de su marido o novio, cinco; a pedido de su madre, cinco; a pedido de su profesor, una; a pedido de su amo por ser sirvientas que salieron sin permiso de la casa en que trabajaban, cinco; a petición de un juez (no dice por qué) dos; una esclava mal portada y otra depositada por orden de su amo. ${ }^{34}$

El cuadro 1, elaborado a partir de los libros de visitas de 1765, 1799 y 1800, indica que los delitos sexuales fueron la principal causa por la cual las mujeres eran recluidas en la cárcel, seguido por el robo y el consumo de licor ${ }^{35}$.

34 A causa de los terremotos de Santa Marta de 1773, la ciudad de Santiago de Guatemala fue abandonada y adquirió el nombre de "la antigua Guatemala". Fue la capital del reino trasladada a otro sitio que, por no estar rodeada de volcanes, supuestamente era más segura, aunque no resultó ser cierto ya que se asentó cerca de una falla teutónica mayor. A la nueva ciudad se le puso en nuevo nombre de la Nueva Guatemala de la Asunción, que es el nombre que aún tiene. 35 AGCA, en "Libro de visitas", año 1765, leg. 2260, exp. 16402; año 1799 y 1800; A.1.2.8, leg. 4011, exp. 30605.
Una mirada comparativa al tipo de penas que recibían hombres y mujeres por delitos similares refleja, como se deduce del cuadro 2, la mirada asimétrica que pesaba sobre las conductas sexuales que asumían ambos. Por ejemplo, las mujeres que vivían en concubinato recibían una pena de seis meses, mientras que para los hombres no se establecía ninguna pena carcelaria.

Estos libros de visitas también indican que las mulatas y mestizas estaban sobre representadas en las mujeres recluidas en la cárcel. En la visita del 18 de marzo de 1765, por ejemplo, de las 15 mujeres registradas seis eran mulatas, cinco mestizas y cuadro sin origen racial determinado: Juana Bautista por abrir la puerta principal de la Cárcel de Cadenas (prisión para hombres en el Ayuntamiento) para que se fugaran los reos. Una mulata por pedimento de su marido; otra 
Cuadro 2. Comparación de penas entre mujeres y hombres

\begin{tabular}{|l|l|l|}
\hline \multicolumn{1}{|c|}{ Tipo de delito } & \multicolumn{1}{c|}{ Mujer } & \multicolumn{1}{c|}{ Hombre } \\
\hline No querer a su madre & 2 meses & No hay \\
\hline Ebriedad & 1 mes & 1 mes de grillete \\
\hline Robo & 6 meses & De 2 a 6 meses y más si era reincidente \\
\hline Amancebamiento & 6 meses & 6 meses \\
\hline Concubinato & 6 meses & No hay \\
\hline Fuga & Doble de condena & Ídem \\
\hline Hurto & 1 mes & De acuerdo al valor de lo hurtado \\
\hline Chichera & Entre 15 días a1 año & \\
\hline
\end{tabular}

mulata y una mestiza a pedimento de su marido. Una mujer mulata y su pequeño hijo por parir un hijo que no era de su marido. Una soltera mulata por agresora; una mulata por amancebada; una mestiza soltera por amistad ilícita; otra mestiza soltera de 13 años, -que en ese momento ya tenía 25 años (llevaba 13 años presa) por amancebada. También una mujer de 25 años por amancebada con dos hombres; una mulata viuda por amistad ilícita y sospecha de robo; una mestiza de 28 años, soltera, tejedora, por tener relaciones con muchos hombres, inclusive casados y tener tres hijos de hombres distintos. Una mestiza soltera de 20 años por amancebada con promesa de casamiento, otra que se señala como doncella de la misma edad por amancebada con un indio casado y con un mulato, y otra de 22 años por ser ebria "de profesión" que ya llevaba 15 meses reclusa y que ya había sido detenida muchas otras veces a causa de su vicio. ${ }^{36}$

En estas cárceles las reclusas, aparte de ser privadas de su libertad, eran sometidas a un sistemático proceso de disciplinamiento

36 Así es en la mayoría de los documentos, por ejemplo, en AGCA A1.54 leg. 5351 exp. 45156 de 1754 y A1.14. leg 2291 exp 16821 de 1775. que reproducía las visiones sobre el lugar que debían ocupar las mujeres en el orden colonial. Las cocineras, molenderas, planchadoras, las lavanderas y quienes hacían la limpieza eran las mismas reas. Las mujeres también estaban encargadas de lavar la ropa de los reos de la Real Cárcely de la cárcel de hombres del ayuntamiento de la ciudad. ${ }^{37}$ Este proceso de disciplinamiento y feminización de las instituciones asistenciales y carcelarias se proyectó a la vida republicana, como se deduce de lo establecido en el "Reglamento de la cárcel de mujeres" de 1833. De acuerdo al citado reglamento, las reclusas debían lavar la ropa, planchar, moler el maíz y cocinar para todos los presos (incluyendo nuevamente la cárcel de hombres)..$^{38}$

\section{Consideraciones finales}

Las casas de recogimiento o de arrepentidas fueron un producto de su época. Su creación respondió al interés de las autoridades coloniales de alejar a la mujer de los "peligros sociales" y luchar por la moral pública y la asistencia

$37 \quad$ AGCA B.109.1 leg 2341 exp 46976

38 AGCA A1.54 leg 5351 exp. 45154. 
social. Esa lucha por la moral pública, que respondía a los ideales de la religión, el Estado y la población, fue desarrollada por medio de varias instituciones, entre ellas las casas de recogimiento. Estas casas fueron evolucionando de acuerdo a los cambios a través del tiempo y de las circunstancias. Inicialmente, se creó un colegio para doncellas que se transformó en un recogimiento de mujeres desamparadas, hasta convertirse finalmente en cárceles de mujeres, todas ellas bajo la mística de la salvación eterna.

La institución que se fundó en Santiago de Guatemala fue distinta a las que se instituyeron en España y en otras regiones de Hispanoamérica. La local fue muy sui generis, al albergar en un solo edificio a todo tipo de mujeres con problemas económicos, viudas, mujeres de mala o ligera conducta, pobres o limosneras; a las mujeres que concebían hijos ilegítimos y a quienes estaban en proceso de anulación de su matrimonio; a las mujeres que fueron depositadas por sus familiares, y a quienes eran enviadas a una cárcel preventiva o encerradas para cumplir una condena.

Las casas de recogimiento fueron centros o casas de corrección para mujeres consideradas de mala conducta o públicas pecadoras, donde el ingreso era forzoso y cuyo objetivo era acabar con la delincuencia femenina. Además, respondiendo a su nombre de "casa de arrepentida", a las mismas también ingresaban las que habían decidido romper voluntariamente con su anterior modo de vida. También entraban las que se encontraban en momentos de crisis conyugal (trámite de anulación de matrimonio, divorcio, por faltas contra el honor de su marido), hijas de familia que habían "mancillado" el honor de la familia, viudas, pobres, en depósito por sus padres, maestros, etc.

Durante todo el siglo XVIII las casas de recogimiento y colegios de mujeres se transformaron en cárceles. Sin embargo, debemos distinguir entre las cárceles, en las que se mantenía incomunicada a la detenida durante su proceso para ablandar su resistencia moral y las cárceles penitenciales mucho más benignas, donde se purgaban las condenas. En el caso de Santiago de Guatemala, las funciones de la cárcel preventiva y las penitenciales (purgando una pena) se asignaban a la Casa de Recogidas. Cumplió, para bien o para mal, su función por más de un siglo. Pero, a diferencia de las demás en Hispanoamérica, comenzó a decaer a causa de un fenómeno natural, el terremoto de 1773 y el traslado de la ciudad a un nuevo sitio. A partir de ese momento pasó a ejercer una sola función: la de cárcel de mujeres. 


\section{Bibliografía}

\section{Fuentes Primarias:}

Archivo General de Indias (AGI). Sevilla, España

Archivo General de Centro América (ACCA). Ciudad de Guatemala.

Beleña, E. V., Recopilación Sumaria de todos los Autos Acordados de La Real Audiencia y Sala del Crimen de ésta Nueva España, (prólogo de M. del R. González, México, D.F., Universidad Autónoma de México, 1981.

Diccionario de Derecho Canónico, Paris, Librería e Rosa y Bouret, 1859.

Las Siete Partidas, glosadas por el señor Alfonso Montalvo, Venecia: Luacantonio de Giunta Florentino, 1501.

Recopilación de Leyes de los Reinos de Indias, Madrid, Ediciones Cultura Hispania, 1973.

\section{Fuentes Secundarias:}

Álvarez Estévez, Rolando, La Casa de Recogidas. Una Experiencia Colonial en Cuba. Habana, Cubarte. 2007.

Atondo Rodríguez, Ana María, -El amor venal y la condición femenina en el México colonial, México, D.F., Instituto Nacional de Antropología e Historia, 1992.

Laprostitución en lossiglos XVIyXVII. Una Alternativa para la Mujer, pp.65-83, en https://www. yumpu.com/es/document/view/14150425/ la-prostitucion-en-los-siglos-xvi-y-xvii-una- alternativa-para-la- sitio visitado el 12 de octubre de 2013.

Estrada Monroy, Agustín, Datos para la Historia de Ia Iglesia en Guatemala, Tomo I, Biblioteca "Coathemala" volumen XXVI (Guatemala: Sociedad de Geografía e Historia de Guatemala, 1972.

Fernández Cúcala, Mariana, "La casa de recogidas Nuestra Señora de la Caridad o del Refugio 1848-1870", en: Historia Contemporánea $\mathrm{n}^{0} 21,2000$, págs. 485-521, Universidad de Barcelona http://www. historiacontemporanea.ehu.es/so021con/es/contenidos/gsa/res/en_res/index. php?proxystylesheet $=$ portalweb\&client= portalwe b\&out put = x m I_ no _ dtd \& ents $p=a_{-}$es \&getfields=title. ppd\&hl=es\&num=15\&q=casa+de+recogidas Consultado el 1 de mayo de 2012.

Floody, Claudia, J.T. Cornejo Cancino y C. Conzález Undurraga, Pena de Muerte en Chile Colonial, Centro de Investigaciones Diego Barros Arana, Santiago de Chile, Editores Ril, 2003.

Garland, Lyinda, Byzantine Empresses and Power in Byzanthium $A D$ 527-1203, Londres, Routledge, 1999.

Hernández Méndez, Rodolfo, "La Casa de Doncellas", en: AFEHC, (Asociación de Estudios Históricos en Centroamérica. 2005), http://www.afehc-historia-centroamericana. org/index.php?action=fi_aff\&id=679.

Johnston Aguilar, René, De Santiago de Cuatemala a la villa de Antigua Cuatemala, transformación 
$y$ vida social ante una crisis, Tesis para optar al grado de Licenciado en Historia, Guatemala, Serviprensa, 1997.

Marín, Juan José, "Perspectivas y problemas para una historia social de la prostitución", en: Revista de la Universidad de Costa Rica, número 13. Universidad de Costa Rica, Escuela de Historia, julio, 2001.

MartínezAlcalde, Lidia, "El Colegio-Recogimiento de la Caridad de Lima (1562-1620), Revista Hispania Sacra, Vol. 53, nº 108, Lima. 2001.

Mejía Camilo, Yolanda, "Divorcios en Lima del Siglo XVII (1700-1750)", en: Alma Mater, Lima, 1997.

Méndez Montenegro, Julio César, Autos acordados en la Real Audiencia de Cuatemala, 1561-1807. Documentos inéditos para la historia del Derecho Indiano criollo, México, D.F.: B. Costa-Amic, 1976.

Muriel, Josefina, Los recogimientos de mujeres, respuesta a una problemática social Novohispana (México: UNAM, 1974), pp. 13-28.
Ots Capdequí, José María, El estado español en Indias. México, D.F., Fondo de cultura Económica, 1993.

Pardo, J. Joaquín, Pedro Zamora Castellanos y Luis Luján Muñoz, Guía de Antigua Cuatemala, Guatemala, Editorial José de Pineda Ibarra, 1969.

Pérez Baltazar, María Dolores, Origen de los recogimientosdemujeres(Madrid:Departamento de Historia Moderna, Universidad Complutense, 2007, www.monografias.com. Consultado el 10 de febrero de 2012.

Premo, Bianca, "Penay protección: Delincuencia juvenil y minoridad legal en Lima Virreinal, siglo XVIII", en: Revista Histórica, vol. XXIV, $n^{0} 1$, Pontificia Universidad Católica del Perú, 2000.

Ximénez, Fray Francisco, Historia de La Provincia de San Vicente de Chiapa y Cuatemala de la Orden de Predicadores. Tomo IV, Libro VI. Chiapas, Concultura, 1999. 